\title{
Fatigue Design in Consideration of Simultaneous Train Loading on Double-track Bridges
}

\author{
Yusuke KOBAYASHI, Dr. Eng. \\ Assistant Senior Researcher, \\ Ichiro SUGIMOTO, Dr. Eng. \\ Senior Researcher, Laboratory Head, \\ Steel \& Hybrid Structures, Structures Technology Division
}

With the recent dramatic increase in the daily number of vehicles running on train lines, considering the effects of simultaneous train loading on double-track bridges has become a significant factor in fatigue design for railway steel bridges. In this research, we assessed the effects of simultaneous loading considering several parameters by applying Monte Carlo simulation, and evaluated each parameter's degree of contribution to fatigue damage in simultaneous loading. Using the results obtained, we proposed a new method for practical design calculation that can easily be adopted to consider simultaneous loading on double-track bridges using a coefficient.

Keywords: fatigue design, railway steel bridges, simultaneous loading

\section{Introduction}

In conventional fatigue design for railway steel bridges with double tracks, separate evaluation is performed for fatigue damage caused by trains on each track and the results are combined. However, the condition of trains passing on double tracks on a bridge simultaneously has not yet been considered. This is because the fatigue damage caused by simultaneous train loading is assumed to be negligibly small in comparison to the total fatigue damage the bridge suffers during its lifespan. However, since the daily number of trains has dramatically increased recently, considering the effects of simultaneous train loading has become a significant factor in fatigue design for double-track bridges.

In this research, we assessed the effects of simultaneous loading considering several parameters (e.g., number of trains, bridge span, train speed, etc.) by applying Monte Carlo simulation [1], and evaluated each parameter's degree of contribution to fatigue damage in simultaneous loading. From the results obtained, we proposed a new method for practical design calculation that can easily be used to consider simultaneous train loading on double-track bridges using a coefficient.

\section{Simulation method}

This study applied Monte Carlo simulation to assess the effects of simultaneous loading under various condi- tions. In the simulation, trains were operated between two stations with timetables generated at random, and fatigue damage on a bridge located between the two stations was calculated. The fatigue damage difference according to each parameter was evaluated by the simultaneous loading factor described below.

\subsection{Parameters}

The parameters shown in Table 1 were considered in the simulation. In terms of the design train load, the design standards [2] consider three types of load: Load $\mathrm{M}$ for normal trains, Load EA for locomotives and freight wagons, and Load $\mathrm{H}$ for Shinkansen trains. However, Load EA and Load $\mathrm{H}$ do not contribute to the effects of simultaneous loading because the number of locomotives is extremely small on the type of busy lines for which simultaneous loading needs to be considered and because the probability of simultaneous loading for Shinkansen trains on bridges is very low due to their high speed. Accordingly, the simulation in this research considered only Load M.

For the train speed, values of $72 \mathrm{~km} / \mathrm{h}$ and $25 \mathrm{~km} / \mathrm{h}$ correspond respectively to cases where the bridge is located in the normal section of the train line and where it is located near a station. The stress sharing ratio is the ratio of stress on a bridge member when a train runs on one track of a double-track bridge to that when a train runs on the other track.

Table 1 Simulation parameters

\begin{tabular}{l|l}
\hline Design train load & Load M \\
\hline Bridge span & $1 \mathrm{~m}, 6 \mathrm{~m}, 10 \mathrm{~m}$ to $50 \mathrm{~m}$ (every $5 \mathrm{~m}$ ), $100 \mathrm{~m}$ \\
\hline Daily number of trains & $644,505,425,366,319,210$ (on double track) \\
\hline Train speed & $72 \mathrm{~km} / \mathrm{h}, 25 \mathrm{~km} / \mathrm{h}$ \\
\hline Bridge structure & $\begin{array}{l}\text { Simple-span bridge, two-continuous-span bridge, three-continuous- } \\
\text { span bridge (side span), three-continuous-span bridge (center span) }\end{array}$ \\
\hline Stress sharing ratio & $1.00,0.75,0.50,0.25$ \\
\hline
\end{tabular}




\subsection{Random number generation and computation cycle}

The accuracy of results in Monte Carlo simulation depends on how random numbers are generated and the computation cycle. In this research, the timetables for train operation between the two stations were obtained from random numbers in accordance with following procedure:

1. Random numbers were used to produce one-day timetables for both stations at one cycle computation.

2. The hourly number of trains was fixed as shown in Fig. 1, duplicating different densities in different one-hour periods such as peak hours and off-peak hours.

3. Timetables were generated from normal random numbers with the average and variance as shown in Fig. 2 to avoid biased intervals of train departure.

Here, the data shown in Fig. 1 and Fig. 2 were obtained from statistical analysis of more than 200 actual timetables.

Simulation of train operation for one day using the generated timetables provided the fatigue damage of the bridge located between the two stations, and the simultaneous loading factor to be described in 2.3 was calculated from this damage. After computation with 360 timetables (360 cycles), the effects of simultaneous loading were evaluated from the average of the simultaneous loading factors. The reason for the adoption of 360 cycles is that the average of the simultaneous loading factors converges fully at that cycle.

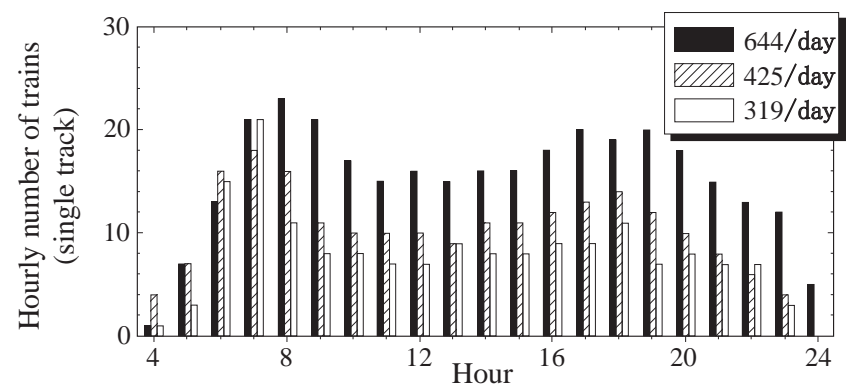

Fig. 1 Example of the number of trains per hour

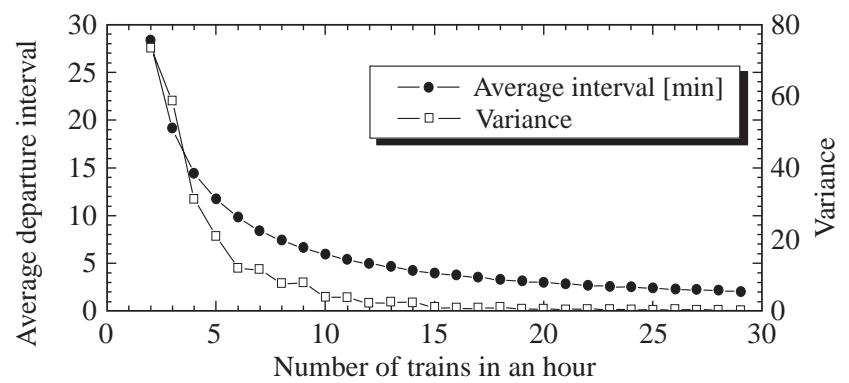

Fig. 2 Average and variance of train departure intervals

\subsection{Simultaneous loading factor}

The contribution of each parameter shown in Table 1 to simultaneous loading can be assessed using the simultaneous loading factor given by the following equation:

$$
\gamma=\left(D_{r} / D_{s}\right)^{1 / m}
$$

where $\gamma$ is the simultaneous loading coefficient, $D_{r}$ represents cumulative fatigue damage [3] computed under various situations of simultaneous loading, and $D_{s}$ is the cumulative fatigue damage computed with the same number of trains as in the case of $D_{r}$ but without the occurrence of simultaneous loading.

Here, $\gamma$ must be expressed as the $m$-th root so that simultaneous loading can be easily taken into account in practical design calculation by multiplying the stress range by $\gamma$, because cumulative fatigue damage is proportional to the $m$-th power of the stress range. Since the simulation was carried out for normal stress, a value of 3 was assigned for $m$ in this research.

\section{Results of simulation}

\subsection{Number of trains and bridge span}

Figure 3 shows the results of simulation under the most general condition with a simple-span bridge structure, a train speed of $72 \mathrm{~km} / \mathrm{h}$ and a stress sharing ratio of 1.0. It can be seen that the simultaneous loading factor increases according to the daily number of trains. It also tends to increase up to a bridge span of $30 \mathrm{~m}$ before slightly decreasing after a value of $35 \mathrm{~m}$ for any number of trains per day.

Figure 4 shows the probability of two trains running on the bridge at the same time. The probability increases according to the number of trains, but the probabilities

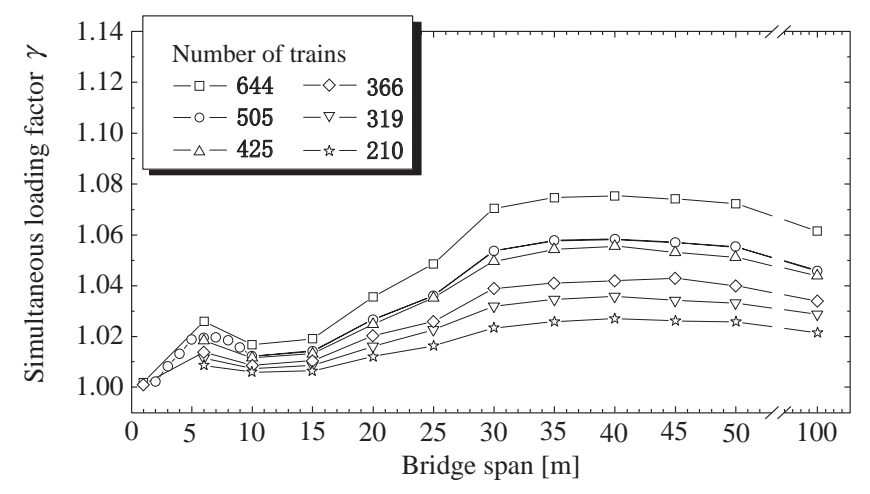

Fig. 3 Simultaneous loading factor according to bridge span and number of trains

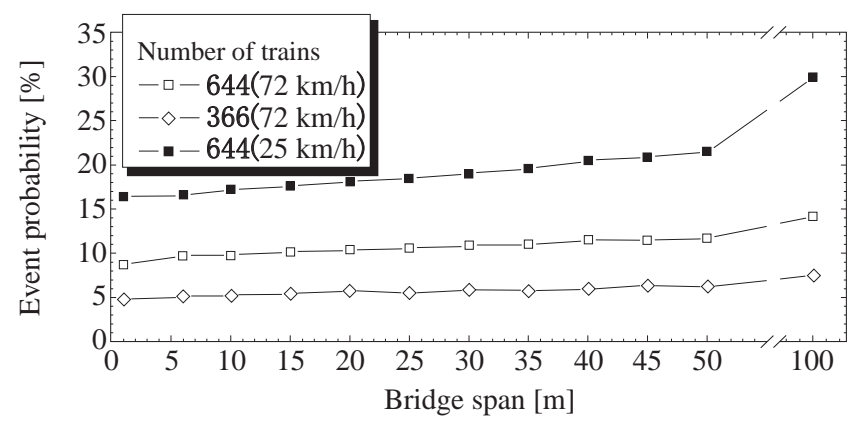

Fig. 4 Probability of two trains running on the bridge simultaneously 
are almost constant relative to the bridge span. The increase in the simultaneous loading factor relative to the bridge span is thought to be due to the waveform at the time when two trains run on the bridge.

\subsection{Train speed}

The simulation results for a train speed of $25 \mathrm{~km} / \mathrm{h}$ are shown in Fig. 5. This simulates the case in which the bridge is located near a station. Here, a simple-span bridge and a stress sharing ratio of 1.0 were adopted.

The simultaneous loading factor at a train speed of $25 \mathrm{~km} / \mathrm{h}$ is higher than that at $72 \mathrm{~km} / \mathrm{h}$, but the tendency of increase up to a bridge span of $30 \mathrm{~m}$ and the slight decrease over $35 \mathrm{~m}$ for $25 \mathrm{~km} / \mathrm{h}$ is very similar to that for the $72 \mathrm{~km} / \mathrm{h}$ example shown in Fig. 3. The event probability of simultaneous loading for a train speed of $25 \mathrm{~km} / \mathrm{h}$ and 644 trains is also shown in Fig. 4. From this figure, the increase in the simultaneous loading factor due to the low speed is thought to be attributable to the increased probability of simultaneous loading.

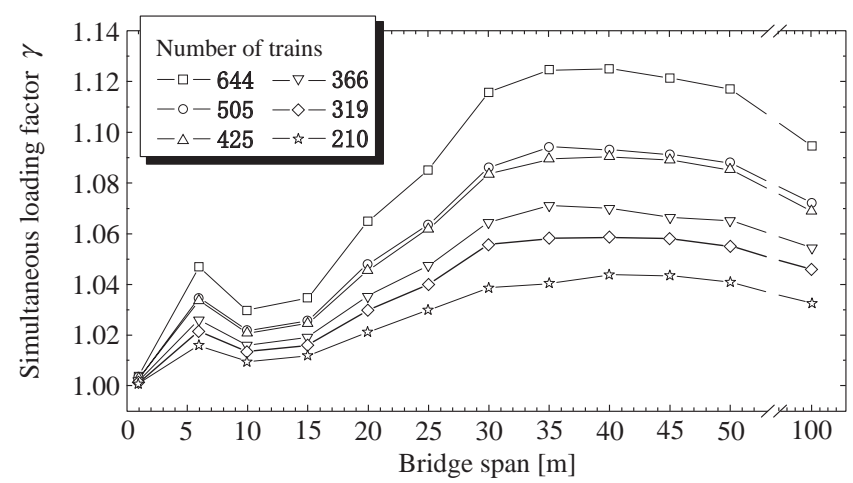

Fig. 5 Simultaneous loading factor for low speed $(25 \mathrm{~km} / \mathrm{h})$

\subsection{Bridge structures}

Figures 6 (a) to (c) show the results of simulation on continuous-span bridges, which adopted a train speed of $72 \mathrm{~km} / \mathrm{h}$ and a stress sharing ratio of 1.0 as parameters. All results show that the simultaneous loading factors are very small compared to the results for the simplespan bridge shown in Fig. 4; the value of the factor shows a maximum of 1.04 .

The influence line of the continuous-span bridge has a negative region. The positive stress generated by a train on one track can be canceled partly by negative ones generated by another train on the other track. This is thought to be why the simultaneous loading factors for continuous-span bridge are relatively small.

\subsection{Stress sharing ratio}

Figure 7 shows the relationship between the simultaneous loading factor and the stress sharing ratio for a simple-girder bridge structure and a span of $35 \mathrm{~m}$. The results show that the factor can be reduced according to the stress sharing ratio.

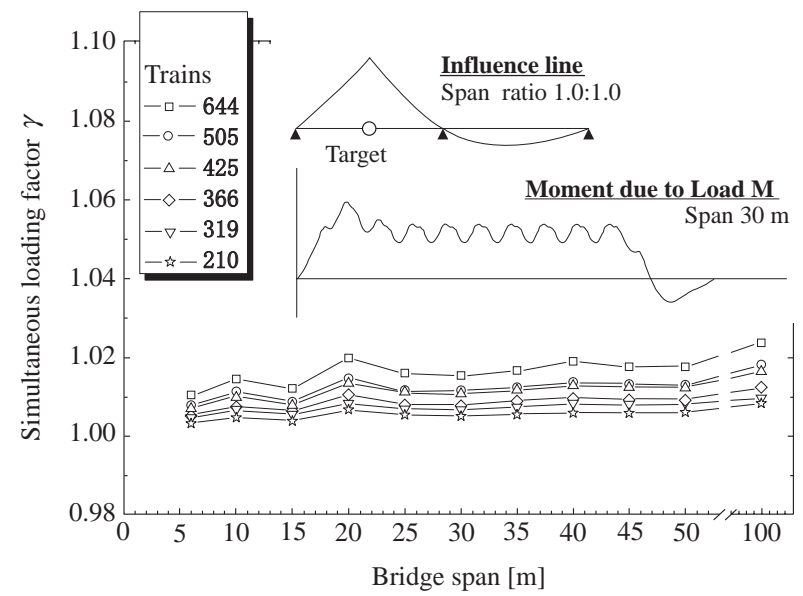

(a) Two-continuous-span bridge

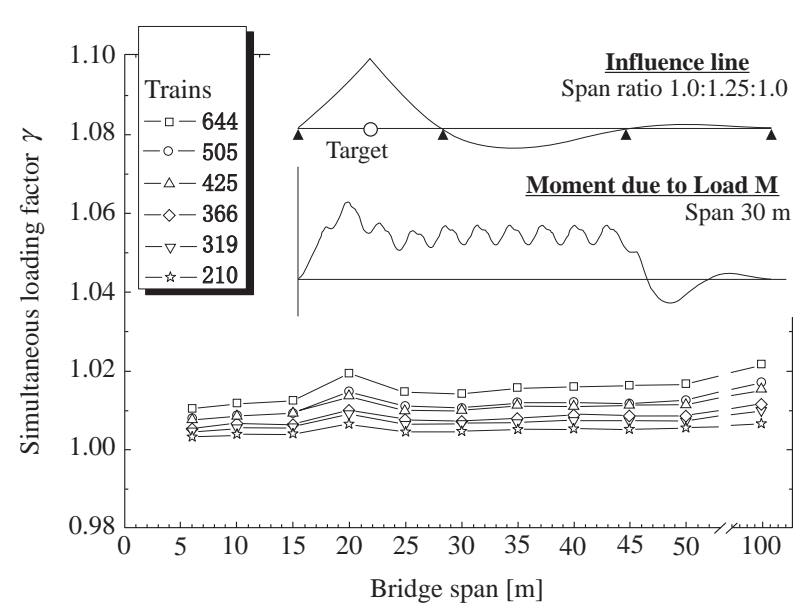

(b) Three-continuous-span bridge (side span)

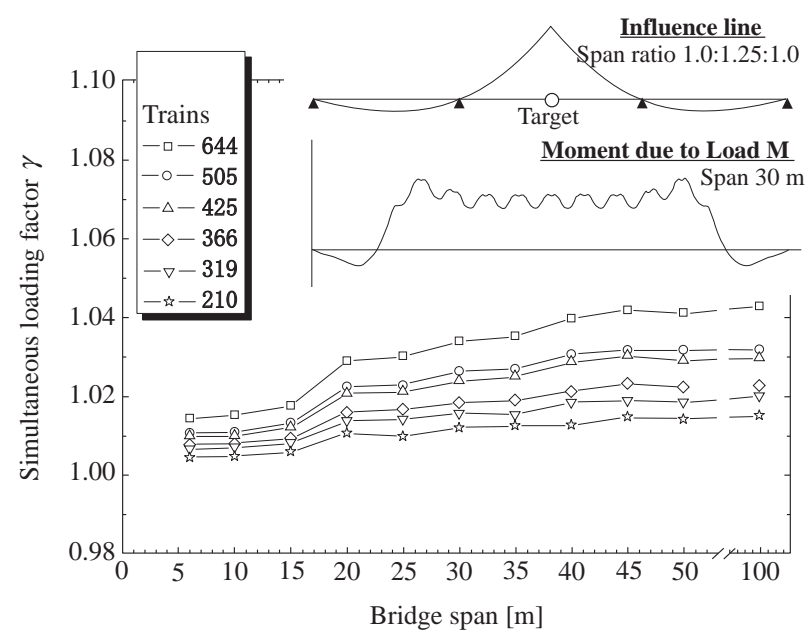

(c) Three-continuous-span bridge (center span)

Fig. 6 Simultaneous loading factors for continuous bridge spans

\section{Introduction of simultaneous loading factor to practical design}

Figure 8 shows the relationships among the simultaneous loading factor, the bridge span and the number 


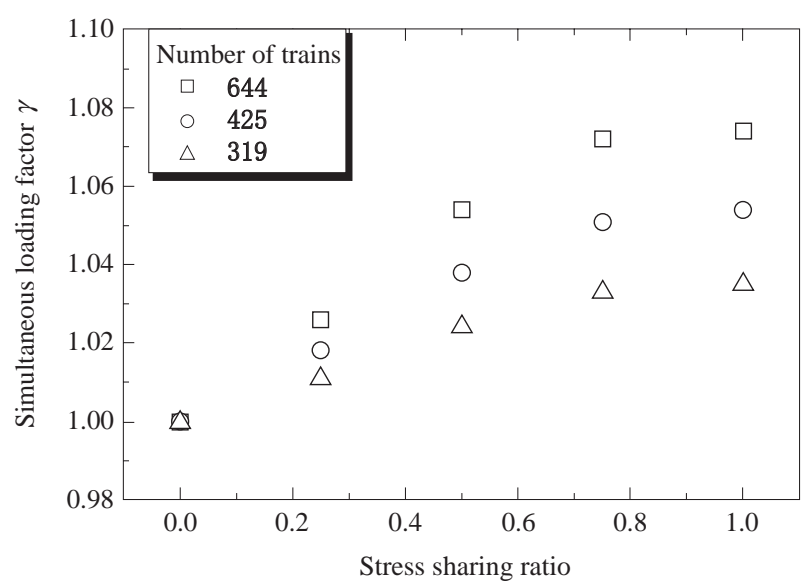

Fig. 7 Simultaneous loading factor according to the stress sharing ratio

of trains for a simple-span bridge structure and a train speed of $72 \mathrm{~km} / \mathrm{h}$. As can be seen, the simultaneous loading factor varies gradually according to changes in the bridge span and the number of trains. However, we proposed using the coefficient $\kappa_{\mathrm{m}}$ as shown in Table 2 for design calculation in consideration of practicality. This coefficient is discretized by the bridge span $(30 \mathrm{~m})$ and the number of trains (400) over which the simultaneous loading factor is more than 1.05, as shown in Fig. 8. This discretization was defined by considering the relation to the impact factor, which was also a function of train speed.

The other parameters based on the simulation results in this research could be utilized in practical design calculation according to the following procedures:

1. The coefficient $\kappa_{\mathrm{m}}$ shown in Table 3 can be applied to the fatigue design of the bridge near the station (lowspeed zone).

2. For continuous girders, the effects of simultaneous loading can be ignored because the factors are lower than 1.05 in all the conditions shown in Figs. 6 (a) to (c).

3. The coefficient $\kappa_{\mathrm{m}}$ can be reduced according to the stress sharing ratio.
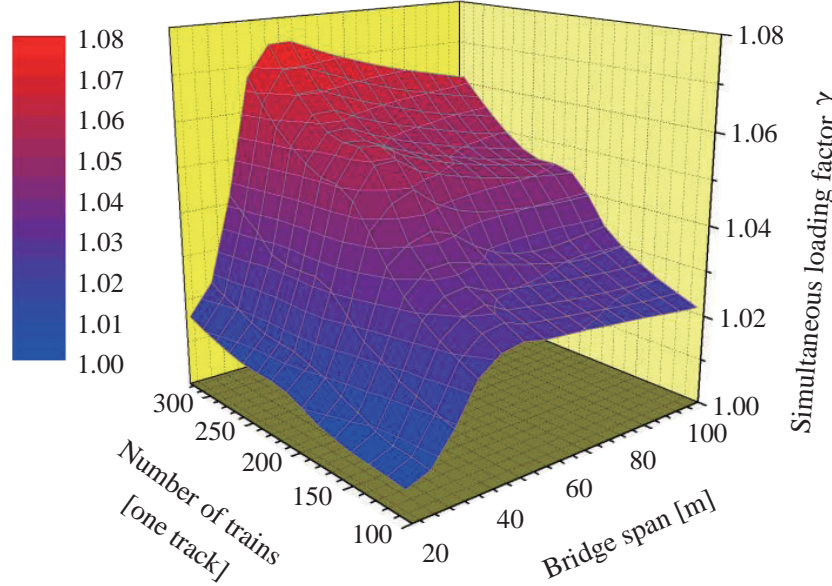

Fig. 8 Relationships among simultaneous loading factor, bridge span and number of trains
Table 2 Simultaneous loading coefficient $\kappa_{m}$ for practical design

\begin{tabular}{c|c|c}
\hline \multirow{2}{*}{$\begin{array}{c}\text { Number of trains } \\
\text { [per day] }\end{array}$} & \multicolumn{2}{|c}{ Bridge span [m] } \\
\cline { 2 - 3 } & Under $30 \mathrm{~m}$ & Over $30 \mathrm{~m}$ \\
\hline Under 400 & \multicolumn{2}{|c}{1.00} \\
\hline Over 400 & 1.00 & 1.05 \\
\hline
\end{tabular}

Table 3 Simultaneous loading coefficient $\kappa_{m}$ for practical design (for low-speed zone)

\begin{tabular}{c|c|c|c}
\hline \multirow{2}{*}{$\begin{array}{c}\text { Number of trains } \\
\text { [per day] }\end{array}$} & \multicolumn{3}{|c}{ Bridge span [m] } \\
\cline { 2 - 4 } & Under 20 m & Over 20 m & Over 30 m \\
\hline Under 300 & \multicolumn{3}{|c}{1.00} \\
\hline Over 300 under 500 & 1.00 & 1.05 & 1.10 \\
\hline Over 500 & 1.00 & \multicolumn{3}{|c}{} \\
\hline
\end{tabular}

\section{Conclusions}

In this research, we quantitatively assessed the effects of simultaneous loading on bridge fatigue damage using simultaneous loading factor values computed from Monte Carlo simulation. The results obtained can be summarized as follows:

(1) The simultaneous loading factor increases according to the number of trains due to the increased probability of two trains running on the bridge simultaneously.

(2) The simultaneous loading factor also increases according to the bridge span, but decreases slightly for span values over $35 \mathrm{~m}$.

(3) In the case of low train speeds, the simultaneous loading factor becomes high due to increased probability.

(4) The effects of simultaneous loading can be ignored for continuous-span bridges.

(5) The simultaneous loading factor can be reduced according to the stress sharing ratio.

Based on the above results, we have proposed a method that considers the effects of simultaneous loading for practical bridge design using the simple coefficient $\kappa_{\mathrm{m}}$.

\section{Acknowledgment}

This work was financially supported in part by the Japanese Ministry of Land, Infrastructure and Transport.

\section{References}

[1] Takeshi MORI, "Simultaneous loading factor for fatigue design load of highway bridges with two traffic lanes," Journal of structural mechanics and earthquake engineering, Japan Society of Civil Engineering, No. 759/I-67, pp. 247-258, 2004.

[2] Railway Technical Research Institute, Design Standards for Railway Structures and Commentary (steel and composite structures), Maruzen Co., Ltd., 2009.

[3] Japanese Society of Steel Construction, Fatigue design recommendations for steel structures, Gihodo Shuppan Co., Ltd., 1993. 